\title{
Why I . . . leave tampons in loos
}

\section{Josie Cheetham tells Jacqui Wise why she set up a scheme to provide emergency sanitary protection for junior doctors}

\section{Jacqui Wise}

London, UK

Josie Cheetham's idea for her sanitary protection on site (SOS) scheme came about after talking to friends and colleagues who described the difficulties of having a period while at work.

"Friends told me of bleeding through their scrubs on a ward round and not being able to take a break for several hours," says Cheetham, a junior doctor at Aneurin Bevan University Health Board in Wales. "Others described having to resort to using toilet roll because they didn't have any sanitary products with them. That shouldn't have to happen. It's undignified and makes women feel anxious."

A junior doctor's shift can last for up to 13 hours and access to rest breaks can be limited, so it can be difficult to find the time to find sanitary products, Cheetham says.

Additionally, hospital shops tend to open only from 9 am to 5 pm on weekdays, making it difficult for staff working at night or on weekends or bank holidays to be able to buy sanitary products on site.

"Because our shift patterns are so variable it's easy to turn up to work without any 'just in case' sanitary products and realise that your period has started halfway through the shift or that it is heavier than expected," says Cheetham.

Female doctors frequently have to resort to asking colleagues for spare tampons or pads, she says, but that can prove difficult if there aren't many other female staff members.

Since February, Cheetham has placed seven SOS boxes in the toilets of the junior doctors' messes in each of the three acute hospitals in her health board and is about to put more in the board's two emergency departments. The boxes are filled with sanitary towels, tampons, and panty liners of different absorbencies.
To advertise their presence Cheetham put up posters, emailed the postgraduate education centres, and posted on junior doctors' WhatsApp groups. The response so far has been very positive. "Doctors have said they feel their wellbeing is being valued," she says.

So far Cheetham has financed the scheme herself, which has cost $£ 64$ ( $€ 71$; \$80) for seven plastic airtight boxes and $£ 30$ for their content. She estimates it would only cost $33 p$ a week to keep the boxes filled as the products are only used in emergencies. She is hoping that the low cost initiative will be funded by the local health board and eventually be adopted across Wales.

In the future she would like to expand the scheme so that all female staff can access the boxes, not just junior doctors.

"I want to encourage others to think about their wellbeing and recognise how small changes at work can make a big difference," says Cheetham. "Doctors are not superhuman and we deliver better care when our needs are met, such as being able to eat when hungry and take toilet breaks."

\section{How to set up an SOS box scheme}

Identify a suitable place in a communal area that can be accessed discreetly

- Buy airtight plastic boxes and fill with a range of sanitary products

- Advertise the box through email, social media, and posters

- Approach mess presidents for funding

- Survey female junior doctors about their needs and experience of using the boxes and present the findings to your health board or trust for longer term funding. 